by a moulded insole which spread the distribution of weight more evenly. The Bath authors warn that the shoe should be deep enough to take such an insole; otherwise dorsal pressure lesions will occur. Hallux rigidus was noted in partial form in 43 feet, the average duration of rheumatoid disease being $12 \cdot 4$ years; complete hallux rigidus occurred in 12 feet with an average disease duration of $25 \cdot 2$ years. Hyperextension of the interphalangeal joint of the great toe was seen in 83 feet, 43 having the "chisel toe syndrome," where the nail presses up into the toecap of the shoe.

What can be done for all these poor sufferers with toes like these? Their life is tedious enough without their being unable to walk without discomfort in the big toe. Dixon and his colleagues emphasise that not only should we appreciate what deformities are present in our rheumatoid patients' feet and what effect they have on function, but we must also understand that these deformities are not static but change as the years go by. Giving a patient some shoes which may be useful for only a few months is fully justified, as during these few months they may help walking very greatly and enable the patient to keep at work. The whole system depends on rapid delivery to the patient, yet too often there is a three months or more delay. Research is urgently needed into improved methods of shoe manufacture for diseased or deformed feet, for better shoes more quickly delivered throughout the country would improve patient mobility and lessen time off work and disability payments. Much more time could usefully be spent in the clinic fitting the patient for shoes; surgical operations on great toe deformities could often be avoided by so doing. For the poor rheumatoid at present, to misquote Kipling, there's all too often no discharge in peace or war.

${ }^{1}$ Jacoby, R K, et al, Rheumatism and Rehabilitation, 1976, 15, 143.

\section{Chemoprophylaxis of malaria}

Anyone planning holidays or other trips abroad should remember that the simplest method of preventing malaria (and several other serious diseases) is not to travel to endemic areas. However, indigenous peoples, expatriate residents, and international travellers cannot avoid the risk in that way, and all need to take drugs if they are to prevent malaria.

The choice is least difficult for the international traveller, since his drugs will need to be taken only for weeks or months rather than years, and toxicity is less likely to occur. The prophylaxis of malaria has received regular attention in the $B M \mathcal{F}^{1-5}$ In 1973 the World Health Organisation prepared a special issue of the Weekly Epidemiological Record, ${ }^{6}$ which has now been updated, ${ }^{7}$ giving information on the risks of malaria for international travellers. This tabulates the risks of malaria for all the countries and areas of the world and then discusses preventive measures, including drugs. Personal measures include the screening of windows, aerosol sprays, mosquito netting around beds, and the use of insect repellent.

In areas where falciparum malaria is sensitive to chloroquine WHO recommends that any one of four drugs may be used for prophylaxis: two 4-aminoquinolines (chloroquine and amodiaquine) and two inhibitors of folic acid metabolism (proguanil and pyrimethamine). The doses for children need to take account of age, body weight, and general health.
The usual adult dose of chloroquine is $300 \mathrm{mg}$ weekly begun one week before exposure, but in highly malarious areas WHO recommends $300 \mathrm{mg}$ twice weekly or $100 \mathrm{mg}$ daily. American authorities recommend chloroquine (a drug developed in the United States) rather than proguanil because it is a more powerful curative drug and Plasmodium falciparum is less often resistant. ${ }^{8}$ The British argue that chloroquine should not be used for prophylaxis because resistance to the drug may thereby be induced and its therapeutic value eventually impaired. ${ }^{9}$ This hypothesis is logical but has never been proved. Retinopathy has been described ${ }^{1011}$ in a few patients taking $100 \mathrm{mg}$ chloroquine daily (instead of the usual $300 \mathrm{mg}$ a week) for about 10 years-a total of over $365 \mathrm{~g}$-but it was not detected ${ }^{12}$ in 57 US Foreign Service personnel who had taken $300 \mathrm{mg}$ weekly for over five years (over $78 \mathrm{~g}$ ). WHO considers that the risk of retinopathy begins when more than $100 \mathrm{~g}$ of chloroquine has been ingested and advises that an alternative should then be taken. ${ }^{7}$ Amodiaquine (standard adult dose $400 \mathrm{mg}$ weekly) is sometimes more effective than chloroquine, but it is not widely used.

Proguanil was developed in Britain and is recommended by most British authorities because it is not used for treatment, it is rarely toxic, and is given daily. WHO considers that a weekly dose is more easily forgotten than a daily dose and that omission of a weekly dose may be more serious; its advice, therefore, is that a daily dose regimen is preferable. However, proguanil is an antifole, like pyrimethamine, and resistance to both drugs does occur in parts of Africa. ${ }^{13}$ Both drugs, unlike chloroquine, act slowly against established infections of malaria, and this may reflect their chemosuppressive potency. The adult doses are $100-200 \mathrm{mg}$ proguanil daily and $25-50 \mathrm{mg}$ pyrimethamine weekly. Chloroproguanil, $20 \mathrm{mg}$ weekly, is a longer-acting derivative of proguanil but it is seldom used. Attacks of malaria do occur despite the regular ingestion of any of these drugs and comparative prospective studies (between chloroquine and proguanil) should be performed. Unofficially it is sometimes recommended that both should be takenchloroquine weekly and proguanil daily.

In areas where falciparum malaria is resistant to treatment with chloroquine the most effective chemosuppressant ${ }^{14}$ is the synergistic combination of pyrimethamine $25 \mathrm{mg}$ and sulfadoxine $500 \mathrm{mg}$ (Fansidar). This is a fairly well balanced combination because the elimination half-lives of pyrimethamine (about 100 hours) and sulfadoxine (about 200 hours) are similar. The drug is effective when given every one, two, or four weeks, but two tablets every two weeks is the standard adult dose. Long-acting sulphonamides can cause StevensJohnson syndrome, but no serious toxicity has occurred in several studies of Fansidar when used for up to 12 months for the chemosuppression of malaria. ${ }^{15-18}$ For the first time the WHO has now ${ }^{7}$ recommended Fansidar for the short and medium term prophylaxis in areas of chloroquine-resistant falciparum malaria.

After leaving the malarious area it is important for a traveller to continue drug prophylaxis for eight weeks to reduce the chance of an attack of the disease. Falciparum malaria is often fatal unless treated early. Travellers who feel sick should tell a doctor that they think they may have malaria. If the diagnosis is at all possible the doctor may then wish to contact a specialist unit such as the Hospital for Tropical Diseases in London, the Liverpool School of Tropical Medicine, the East Birmingham Hospital, or the City Hospital in Edinburgh.

\footnotetext{
${ }^{1}$ Peters, W, British Medical fournal, 1971, 2, 95.

2 British Medical fournal, 1972, 2, 604.

${ }^{3}$ British Medical fournal, 1973, 1, 691.
} 
${ }^{4}$ British Medical fournal, 1974, 3, 297.

5 Hall, A P, British Medical fournal, 1976, 1, 323

6 World Health Organisation, Information on Malaria Risk for International Travellers, Weekly Epidemiological Record, 1973, 48, 25.

7 World Health Organisation, Information on Malaria Risk for International Travellers, Weekly Epidemiological Record, 1976, 51, 181.

${ }^{8}$ Barrett-Connor, E, Annals of Internal Medicine, 1974, 81, 219.

${ }^{9}$ Macdonald, G, British Medical fournal, 1965, 2, 229.

10 Ravault, M P, Fournal de Médecine de Lyon, 1965, 46, 1391.

11 François, J, and Becker, L de, Annals Oculistique, 1965, 198, 513.

12 Appleton, B, Wolfe, M S, and Mishtowt, G I, Military Medicine, 1973, 138, 225.

13 Taylor, J, British Medical Fournal, 1968, 3, 805.

14 Pearlman, E J, and Hall, A P, Annals of Internal Medicine, 1975, 82, 590.

15 Lucas, A O, et al, Transactions of the Royal Society of Tropical Medicine and Hygiene, 1969, 63, 216.

${ }^{16}$ Laing, A B G, Bulletin of the World Health Organisation, 1970, 43, 513.

17 O'Holohan, D R, and Hugoe-Matthews, J, Southeast Asian fournal of Tropical Medicine and Public Health, 1971, 2, 164.

18 Lewis, A N, and Ponnampalam, J T, Annals of Tropical Medicine and Parasitology, 1975, 69, 1.

\section{The stricken}

In March this year ${ }^{1}$ we reviewed the consequences of acute strokes, which may be expected to affect up to 400 people each year in a district with population of 250000 . Many die, but about 200 survive the first six weeks. What happens to these survivors?

The ten-year follow-up study in Denmark by Marquardsen ${ }^{2}$ of 150 men and 257 women who had recovered from strokes showed that the median survival time was less than four years. Associated heart failure greatly increased the mortality rate; so too did hypertension, especially in those under the age of 70 . Two-thirds of the patients without cardiac failure or hypertension survived five years; one-third of those with only one of these factors survived; but only one-sixth with both factors lived out the five years.

That is the natural history after stroke. Next we should ask whether survivors' needs are met and to what extent. Now that the NHS has been in existence for 28 years it is perhaps surprising that so few studies have been carried out in England on this large group of handicapped and often dependent people, though we have the excellent accounts by Adams $e \mathrm{al}^{3}$ of their work in Northern Ireland. A more recent report from Glasgow by Isaacs, Neville, and Rushford ${ }^{4}$ concentrated on the social consequences of stroke. They described 29 survivors followed for three years or until death from an original group of 76 patients with severe strokes who had been admitted to a special rehabilitation ward. Eleven of the 29 died in the course of the three years. The sample is small, but large enough to indicate notable gaps in the aftercare provided-deficiencies that are probably widespread in Britain.

Of the 29 survivors discharged, 18 were visited by the general practitioner in the first three months, but only three were still visited in the second year. Only seven of 25 patients had a home help in the first six months and only six had a district nurse, though after three years 10 of the 18 survivors had both. Domiciliary physiotherapy was recommended for 17 but eight received no treatment.

Before admission 11 patients had been in full-time employment and eight had been occupied in full-time household duties. After discharge none returned to work and only three did some household work. Eight never left their houses for a year. Only three managed a daily unaccompanied walk. None went out by public transport, none to the hairdresser or place of entertainment. Nine claimed attendance allowance; two were paid in full and four for night attendance only.
What was the effect of all this on their outlook and morale, the effect of the handicap itself, and the effect of sudden enforced retirement from work and the companionship which work affords? Happily married patients were well supported by their spouses in spite of difficulties in home management caused by irritability, frustration, consequent aggressiveness, and feelings of depression. Some refused to eat, some were messy, some voracious. Some deposited urine and faeces in inappropriate places. In recommending that more could be done for the survivors of stroke Isaacs et al specified in particular the greater use of day hospitals and the formation of stroke clubs with or without the help of the Women's Royal Voluntary Service. We also need greater awareness by all concerned for the aftercare of stroke patients and easier access to physiotherapy, occupational therapy, speech therapy, and the other services developed in geriatric and other day hospitals. Day hospitals could well become the focal point of rehabilitation in the community. This aim has been embodied in the new units constructed to DHSS design in the West Midlands and elsewhere, but many, many more are needed.

1 British Medical fournal, 1976, 1, 541.

2 Marquardsen, J, Age and Ageing, 1975, suppl, p 41.

${ }^{3}$ Adams, G F, Cerebrovascular Disability and the Ageing Brain. Edinburgh, Churchill Livingstone, 1974.

4 Isaacs, B, Neville, Y, and Rushford, I, Age and Ageing, 1976, 5, 188.

\section{Low oestrogen oral contraceptives}

In 1969 the Committee on Safety of Medicines recommended that the maximum oestrogen dosage in oral contraceptives should be $50 \mu \mathrm{g}$ per day. Two oestrogens are used in oral contraceptives-ethynyl oestradiol and its 3-methyl ether, mestranol. Ethynyl oestradiol is more potent and more popular than mestranol, which first appeared as a more or less accidental contaminant of the progestogen element in oral contraceptives. In some newer preparations the content of ethynyl oestradiol has been reduced to as low as $30 \mu \mathrm{g}$ and even $20 \mu \mathrm{g}$, which appears to be the smallest amount compatible with the desired biological activity.

After six years of low-oestrogen oral contraceptives enough data have accumulated for the position to be assessed. Of course the reason for the low oestrogen was to reduce the incidence of untoward side effects, particularly thromboembolism. The project by the Royal College of General Practitioners ${ }^{1}$ suggests that low-dose oestrogen has reduced the incidence of thrombosis by about $25 \%$. Nor has the reduction in oestrogen content been accompanied by a notable decline in their contraceptive efficiency. A recent study ${ }^{2}$ showed an uncorrected pregnancy rate of 0.16 per 100 woman years. The same study also showed that, as expected, the incidence of breakthrough bleeding is higher on low-dose oestrogens, though at $5 \cdot 2 \%$ it has not proved a serious obstacle to their use.

Even when the oestrogen content is reduced to as little as $30 \mu \mathrm{g}$ of ethynyl oestradiol per day the main basis of the contraceptive action is still by suppression of ovulation. A recent investigation ${ }^{3}$ showed that plasma $\mathrm{FSH}$ levels are depressed and that the midcycle surge of $\mathrm{LH}$ is abolished. The contraceptive efficiency may owe something to changes in cervical mucus induced by the progestogen, which prevent sperm penetration, but a failure to ovulate and depressed 